\title{
Rhodium diphosphite pincer complexes. Rare preferred in-plane olefin conformation in square-planar compounds $\dagger+$
}

\author{
Miguel Rubio, ${ }^{a}$ Andrés Suárez, ${ }^{a}$ Diego del Río, ${ }^{a}$ Agustín Galindo, ${ }^{* b}$ Eleuterio Álvarez ${ }^{a}$ and Antonio Pizzano*a
}

Received 23rd November 2006, Accepted 5th December 2006

First published as an Advance Article on the web 13th December 2006

DOI: 10.1039/b617164h

Square-planar ethylene rhodium derivatives bearing pincer diphosphite ligands have been prepared and characterized, they display a rare in-plane coordination which, based on DFT calculations, has been mainly attributed to steric effects.

The orientation of a coordinated olefin is an aspect of fundamental importance in organometallic chemistry with repercussion in processes involving olefin transformation like catalytic hydrogenation, hydroformylation or olefin metathesis among others. ${ }^{1}$ The preferred alkene conformation has been explained as the result of an interplay between electronic and steric factors: the orientation of the proper metal-centred orbital back donating to the $\pi^{*}$ olefin orbital and the steric repulsion between the alkene and adjacent ligands. ${ }^{2}$ Thus, the overall preference is dependent on the geometry of the olefinic complex, and in the case of square-planar compounds, an upright $(u)$ conformation has almost exclusivelybeen observed. ${ }^{3-6}$ The preference of the $u$ over the<smiles>C1[Al]=[V]1</smiles>

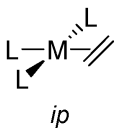

in-plane (ip) conformation has been attributed to the higher steric interaction between the olefin and the two cis ligands in the latter structure. In comparison, electronic effects look to play a minor role, as the $\pi$ component of the metal-olefin bond is of similar energy in both conformations. ${ }^{2}$ From these arguments, it looks feasible that an arrangement of L ligands lowering encumbrance in the coordination plane while increasing in the axial direction, could favour the ip conformation. Indeed, we present in this contribution new diphosphites $\mathbf{2}$, capable to act as pincer ligands in Rh complexes, ${ }^{7}$ which display these steric features and give rise to ethylene square-planar derivatives with an ip conformation. The series of complexes described herein are, in addition, the first $\mathrm{Rh}$ examples with diphosphite pincer ligands. ${ }^{8}$

Compounds 2 have been prepared from resorcinol and either flexible chlorophosphite 1a or enantiomerically pure $\mathbf{1 b}$ (Scheme 1). Reaction between 2 and $\mathrm{Rh}(\mathrm{Cl})\left(\mathrm{PPh}_{3}\right)_{3}$ led to compounds $\mathbf{3 a}$ and $\mathbf{3 b}$ (Scheme 2). This transformation involves dis-

anstituto de Investigaciones Químicas, Consejo Superior de Investigaciones Cientificas and Universidad de Sevilla, Avda Américo Vespucio no. 49, Isla de la Cartuja, 41092, Sevilla, Spain.E-mail: pizzano@iiq.csic.es; Fax: 34 954460565; Tel: 34954489556

${ }^{b}$ Departamento de Química Inorgánica, Universidad de Sevilla, Aptdo 553, 41071, Sevilla, Spain.E-mail: galindo@us.es; Fax: 34 954557153; Tel: 34 954557161

$\dagger$ The HTML version of this article has been enhanced with colour images. † Electronic supplementary information (ESI) available: Representative experimental procedures, crystallographic information for $\mathbf{5 a}$ and $\mathbf{5 b}$, computational details and calculated data for model compounds I-VI. See DOI: $10.1039 / \mathrm{b} 617164 \mathrm{~h}$

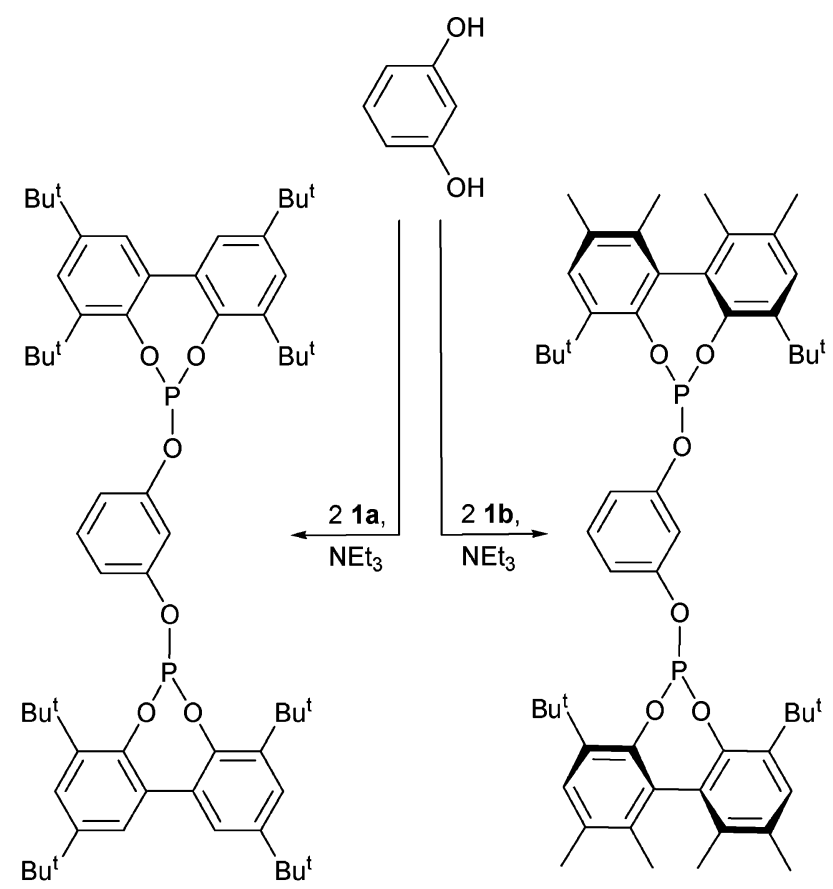

$2 \mathbf{a}$

$2 \mathbf{b}$

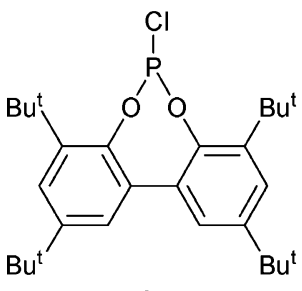

1 a

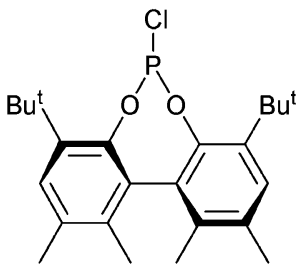

$1 \mathrm{~b}$
Scheme 1 Synthesis of diphosphites 2.

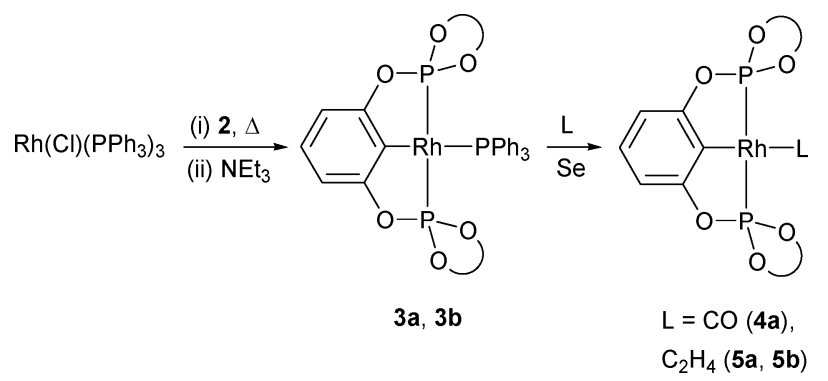

Scheme 2 Synthesis of pincer complexes.

placement of two $\mathrm{PPh}_{3}$ ligands and cyclometallation of $\mathbf{2}$, generating the corresponding anionic tridentate ligand (generically named here PCP). The $\mathrm{PPh}_{3}$ in 3 is labile and can readily be displaced. Thus, carbonyl derivative $\mathbf{4 a}$ is rapidly formed upon exposure of 
a solution of 3a to an atmosphere of CO. However, the displaced phosphine complicates isolation of 4a. Most useful, addition of Se to the reaction mixture quenches the phosphine as $\mathrm{P}(\mathrm{Se}) \mathrm{Ph}_{3}$, which can be readily removed from the mixture. This protocol has also been applied to the preparation of ethylene derivatives $\mathbf{5 a}$ and $\mathbf{5 b}$. ${ }^{9} \S$

An important characteristic of these PCP ligands is the acceptor character of the phosphite groups that causes a reduced backdonating ability of fragment Rh-PCP. ${ }^{10}$ This feature is evident in the IR spectrum of compound $\mathbf{5 a}$, that displays the $v(\mathrm{CO})$ band at $2017 \mathrm{~cm}^{-1}$, considerably shifted to higher energy $\left(60 \mathrm{~cm}^{-1}\right)$ from that of an analogous $\mathrm{Rh}$ carbonyl bearing a pincer diphosphine. ${ }^{11}$

Complexes $\mathbf{5}$ have been studied by X-ray diffraction (Fig. 1 and 2). The coordination of the PCP ligand in the pincer fashion is characterized by a $\mathrm{P}(1)-\mathrm{Rh}-\mathrm{P}(2)$ angle of $155^{\circ}$. This angle is appreciably smaller than that found in complexes derived from pincer diphosphines, which usually cluster around $165^{\circ} .{ }^{12}$ Also interesting, the biphenyl groups of $\mathbf{5 a}$ have the same configuration (while they are conformationally flexible in solution) giving rise to a chiral structure. Another remarkable feature of the Rh-PCP fragment is its planarity, in contrast with the puckered structures usually produced by pincer diphosphines. ${ }^{13}$ This backbone pla-

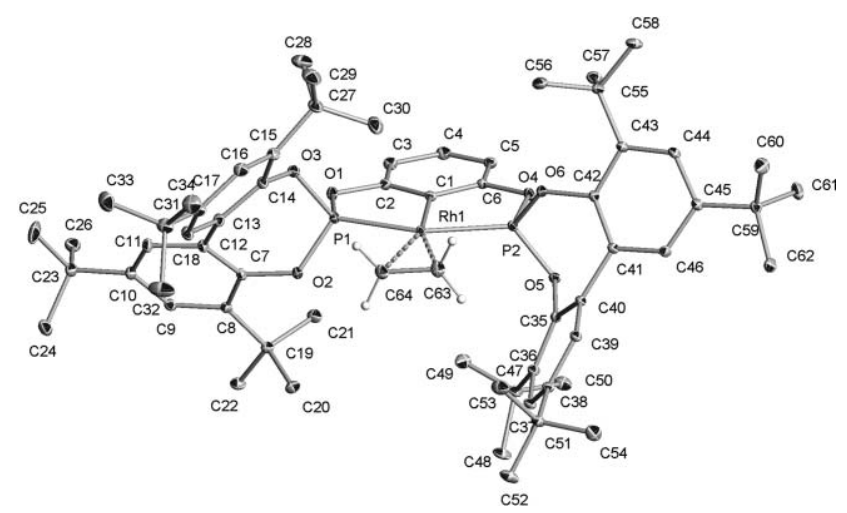

Fig. 1 ORTEP view of complex 5a. H atoms (except for ethylene ligand) and solvent molecule have been omitted for clarity. Selected bond lengths $(\AA)$ and angles $\left({ }^{\circ}\right)$ : $\mathrm{Rh}-\mathrm{P}(1)=2.2076(3), \mathrm{Rh}-\mathrm{P}(2)=2.2165(3)$, $\mathrm{Rh}-\mathrm{C}(1)=2.0233(12), \mathrm{Rh}-\mathrm{C}(63)=2.2353(14), \mathrm{Rh}-\mathrm{C}(64)=2.2184(14)$, $\mathrm{C}(64)-\mathrm{C}(63)=1.377(2), \mathrm{P}(1)-\mathrm{Rh}-\mathrm{P}(2)=155.490(13)$.

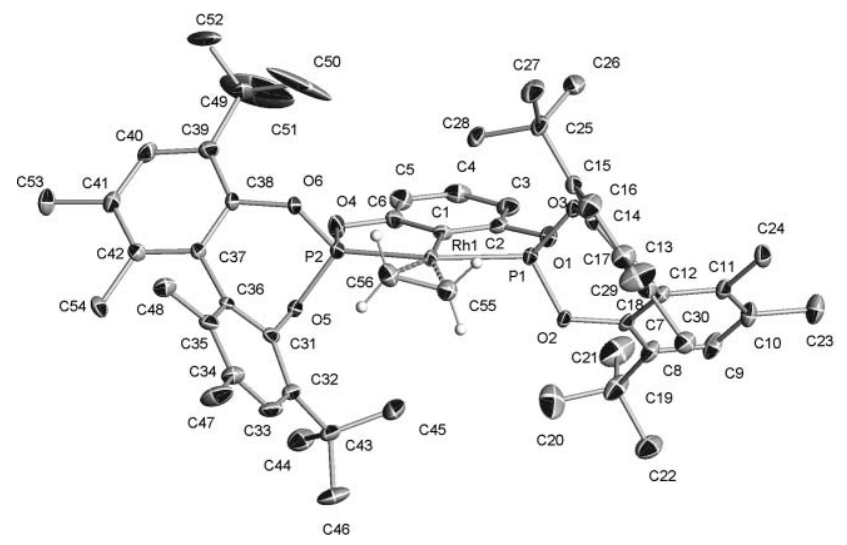

Fig. 2 ORTEP view of complex $\mathbf{5 b}$. $\mathbf{H}$ atoms (except for ethylene ligand) and solvent molecule have been omitted for clarity. Selected bond lengths $(\AA)$ and angles $\left({ }^{\circ}\right)$ : Rh-P(1) = 2.2237(7), Rh-P(2) = 2.2096(7), Rh-C(1)= 2.019(3), $\mathrm{Rh}-\mathrm{C}(55)=2.228(3), \mathrm{Rh}-\mathrm{C}(56)=2.230(3), \mathrm{C}(55)-\mathrm{C}(56)=$ 1.353(4), $\mathrm{P}(1)-\mathrm{Rh}-\mathrm{P}(2)=155.37(3)$. narity is a common feature with other complexes described in the literature bearing oxygen atoms in the bridge. ${ }^{8,14}$ Most noteworthy, coordinated ethylene shows an unexpected in-plane conformation, with a small angle of $7.4(\mathbf{5 a})$ and $13.0^{\circ}(\mathbf{5 b})$ between planes defined by Rh-PCP and Rh- $\eta^{2}-\left(\mathrm{C}_{2} \mathrm{H}_{4}\right)$. The $\mathrm{C}=\mathrm{C}$ bond length is similar for 5a $(1.38 \AA)$, while slightly lower for $\mathbf{5 b}(1.35 \AA)$, to the mean value observed in other rhodium ethylene derivatives $(1.38-1.39 \AA){ }^{12}$

Due to its $C_{2}$ symmetry, complex $\mathbf{5 b}$ is not suitable to study ethylene rotation. ${ }^{15}$ To ascertain the participation of this process we have prepared the less-symmetric propene derivative $\mathbf{6 b}$ by simply treating $\mathbf{5 b}$ with an excess of propene (eqn. 1). Compound 6b showed room temperature spectra consistent with an averaged $\mathrm{C}_{2}$ symmetry, indicating olefin rotation. This process could not be frozen, as cooling of the sample down to $190 \mathrm{~K}$ did not split $\mathrm{Bu}^{\mathrm{t}}$ signals in the ${ }^{1} \mathrm{H}$ or ${ }^{13} \mathrm{C}\left\{{ }^{1} \mathrm{H}\right\}$ spectra.<smiles>C=CP1(OC)(c2cccc3c2P2(C=C)(OCCO2)O3)OCCO1</smiles>

5b

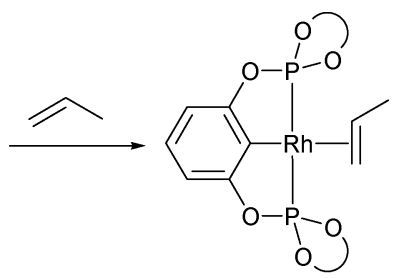

6b
In order to supply additional information about the rare case of $i p$ conformation shown in the X-ray structures of $\mathbf{5}$, we have performed DFT calculations (B3LYP, TZVP basis set; see ESI for detailst) with selected model complexes (Fig. 3). As a reference, the structure of the simplest model trans- $\mathrm{Rh}(\mathrm{Ph})\left(\mathrm{C}_{2} \mathrm{H}_{4}\right)\left(\mathrm{PH}_{3}\right)_{2}(\mathbf{I})$ has been optimized in both $u$ and $i p$ conformations. As expected, the $u$ conformation is considerably more stable by $c a .11 \mathrm{kcal}$ $\mathrm{mol}^{-1}$. In addition, $u$ and $i p$ conformers of pincer model complexes II and III have also been optimized. Interestingly, the energy difference between the two conformers of these models is quite small (about $1 \mathrm{kcal} \mathrm{mol}^{-1}$ ). This fact reflects that the reduction in the $\mathrm{P}-\mathrm{Rh}-\mathrm{P}$ angle, caused by the pincer backbone, stabilizes the $i p$ conformation and then disrupts the regular preference for the $u$ conformer. Likewise, very small energy differences (less than 1 $\mathrm{kcal} \mathrm{mol}^{-1}$ ) in favour of the $i p$ conformation were observed for IV and $\mathbf{V}$. Finally, for model VI, the closest to complex $\mathbf{5 a}$, different conformations for the ethylene ligand were explored as starting geometries. However, the only conformation that appears as a stationary point corresponds to the ip isomer. All our attempts<smiles>C=C[Pb](P)(P)c1ccccc1</smiles><smiles>C=CP1POC2=CC=CC(=C1P)P2</smiles><smiles>C=CP1PCc2cccc3c2P1PC3</smiles>

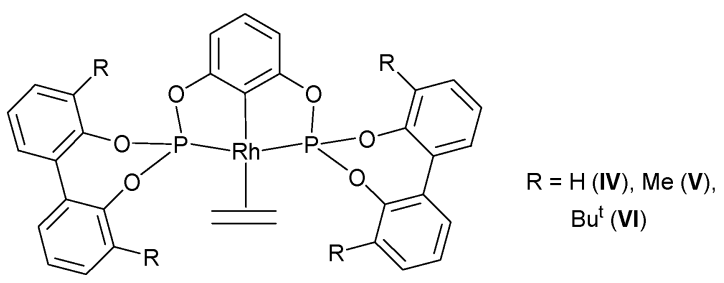

Fig. 3 Model complexes analyzed. 
of optimization of the $u$ conformer converge into the ip one. The structural parameters of VI-ip are in good agreement with the experimental data obtained for 5a. For instance, the computed parameters around the $\mathrm{Rh}-\mathrm{C}_{2} \mathrm{H}_{4}$ moiety $(\mathrm{Rh}-\mathrm{C}, 2.285 \AA$, and $\mathrm{C}-\mathrm{C}$ $1.373 \AA$ ) agrees well with the experimental values found for $\mathbf{5 a}$. Additionally, the calculation reproduces remarkably well structural features of 5 like the planarity of the backbone or the value of the $\mathrm{P}-\mathrm{Rh}-\mathrm{P}$ angle (computed: $155.1^{\circ}$ ). A comparison of the structures of the models IV-VI shows a practically superimposable structure of the common part of the Rh-PCP fragment (see ESI\$). Thus, the cavity around the remaining coordination position is very similar along the series of complexes. In this pocket it is therefore possible to accommodate an ethylene ligand in either $u$ or ip conformation both for IV and V (Fig. 4). Otherwise, for model complex VI the $\mathrm{Bu}^{\mathrm{t}}$ groups significantly reduce the available space of the cavity in the axial direction and while an in-plane ethylene perfectly matches in the pocket, it is not possible to fit a perpendicular one without a significant distorsion of the Rh-PCP fragment.
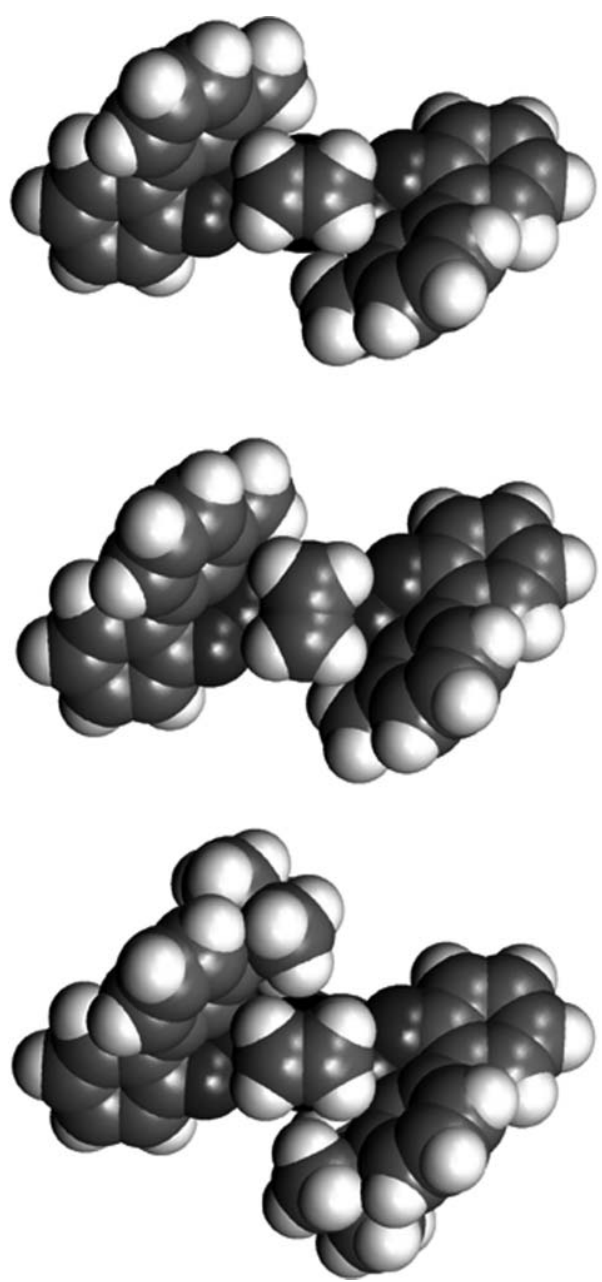

Fig. 4 Space-filling views: V-ip (top), V- $u$ (middle) and VI-ip (bottom).

We have described herein a family of Rh pincer diphosphite complexes. The olefinic derivatives show in the solid-state a rare ip conformation, while olefin rotation in solution is observed. Calculations by DFT methods suggest that the reduction of the $\mathrm{P}-\mathrm{Rh}-\mathrm{P}$ angle releasing hindrance in the coordination plane and the presence of bulky $\mathrm{Bu}^{\mathrm{t}}$ groups pointing towards the axial direction favour this unusual conformation. Further studies about the coordination properties of these ligands and their application in homogeneous catalysis are currently under way.

We gratefully acknowledge Prof. E. Carmona and Dr M. L. Poveda for helpful comments. MEC (Grant PPQ200300975) and Fundación Ramón Areces are acknowledged for financial support. M. R thanks MEC for a FPU fellowship and D. R. 6th FP of EU for a MC-OIF.

\section{Notes and references}

$\S$ Crystal data. 5a $\cdot \mathrm{C}_{5} \mathrm{H}_{12}: \mathrm{C}_{69} \mathrm{H}_{99} \mathrm{O}_{6} \mathrm{P}_{2} \mathrm{Rh}, M=1189.33$, monoclinic, $P 2_{1} / c, a=17.2239(5), b=19.2234(6), c=20.3456(6) \AA, V=6675.6(3) \AA^{3}$, $T=100 \mathrm{~K}, Z=4, \mu=0.351 \mathrm{~mm}^{-1}, 153626$ reflections collected, 20381 independent $(R($ int $)=0.0346), R 1=0.0311, w R 2=0.0797(I>2 \sigma(I)) .5 \mathbf{b}$. $\mathrm{C}_{56} \mathrm{H}_{71} \mathrm{O}_{6} \mathrm{P}_{2} \mathrm{Rh}, M=1004.98$, orthorhombic, $P 2_{1} 2_{1} 2_{1}, a=10.4092(11)$, $b=18.8544(18), c=26.636(3) \AA, V=5227.6(9) \AA^{3}, T=100 \mathrm{~K}, Z=4$, $\mu=0.436 \mathrm{~mm}^{-1}, 45841$ reflections collected, 11402 independent $(R(\mathrm{int})=$ $0.0496), R 1=0.0352, w R 2=0.0717(I>2 \sigma(I))$. CCDC reference numbers 625416 and 625417. For crystallographic data in CIF or other electronic format see DOI: 10.1039/b617164h

1 (a) I. D. Gridnev, M. Yasutake, N. Higashi and T. Imamoto, J. Am. Chem. Soc., 2001, 123, 5268; (b) J. J. Carbó, A. Lledós, D. Vogt and C. Bo, Chem.-Eur. J., 2006, 12, 1457; (c) C. Adlhart and P. Chen, J. Am. Chem. Soc., 2004, 126, 3496.

2 (a) T. A. Albright, R. Hoffmann, J. C. Thibeault and D. L. Thorn, J. Am. Chem. Soc., 1979, 101, 3801; (b) P. J. Hay, J. Am. Chem. Soc., 1981, 103, 1390; (c) T. Ziegler and A. Rauk, Inorg. Chem., 1979, 18, 1558; (d) H. M. Senn, P. E. Blöchl and A. Togni, J. Am. Chem. Soc., $2000,122,4098$.

3 A family of formally tetracoordinated $\mathrm{Pd}$ and $\mathrm{Pt}$ allyl complexes have shown olefin coordination in-plane, however, due to the small bite angle of the allyl ligand, definition of their structure is not unambiguous and both square-planar ${ }^{4}$ and planar-trigonal ${ }^{5}$ geometries have been proposed for them.

4 (a) K. Miki, Y. Kai, N. Kasai and H. Kurosawa, J. Am. Chem. Soc., 1983, 105, 2482; (b) H. Kurosawa, K. Miki, N. Kasai and I. Ikeda, Organometallics, 1991, 10, 1607.

5 A. Musco, R. Pontellini, M. Grassi, A. Sironi, S. V. Meille, H. Rüegger, C. Ammann and P. S. Pregosin, Organometallics, 1988, 7, 2130.

6 Forced alkene coordination in-plane has been observed in diolefin compounds with mutually perpendicular $\mathrm{C}=\mathrm{C}$ bonds: $\mathrm{M}$. H. Rakowsky, J. C. Woolcock, L. L. Wright, D. B. Green, M. F. Rettig and R. M. Wing, Organometallics, 1987, 6, 1211.

7 Structurally similar diphosphites act as bridges in $\mathrm{Rh}$ dinuclear compounds: S. Ini, A. G. Oliver, D. Tilley and R. D. Bergman, Organometallics, 2001, 20, 3839.

8 For Pd derivatives see: (a) R. A. Barber, R. B. Bedford, M. Betham, M. E. Blake, S. J. Coles, M. F. Haddow, M. B. Hursthouse, A. G. Orpen, L. T. Pilarski, P. G. Pringle and R. L. Wingad, Chem. Commun., 2006, 3880; (b) F. Miyazaki, K. Yamaguchi and M. Shibasaki, Tetrahedron Lett., 1999, 40, 7379.

9 For other ethylene derivatives with pincer ligands see:(a) A. C. Sykes, P. White and M. Brookhart, Organometallics, 2006, 25, 1664; (b) H. Salem, Y. Ben-David, L. J. W. Shimon and D. Milstein, Organometallics, 2006, 25, 2292; (c) C. Hahn, J. Sieler and R. Taube, Chem. Ber., 1997, 130, 939 .

10 For other acepting pincer ligands see: (a) E. Kossoy, M. A. Iron, B. Rybtchinski, Y. Ben-David, L. J. W. Shimon, L. Konstantinovski, J. M. L. Martin and D. Milstein, Chem.-Eur. J., 2005, 11, 2319; (b) P. A. Chase, M. Gagliardo, M. Lutz, A. L. Spek, G. P. M. van Klink and G. van Koten, Organometallics, 2005, 24, 2016.

11 A. Weisman, M. Gozin, H.-B. Kraatz and D. Milstein, Inorg. Chem., 1996, 35, 1792.

12 For, QUEST3D-search details see ESI\$.

13 For representative examples see: (a) H.-B. Kraatz and D. Milstein, J. Organomet. Chem., 1995, 488, 223; (b) J. Cámpora, P. Palma, D. del Río and E. Álvarez, Organometallics, 2004, 23, 1652.

14 I. Göttker-Schnetmann, P. White and M. Brookhart, J. Am. Chem. Soc., 2004, 126, 1804.

15 L. Cavallo, M. E. Cucciolito, A. De Martino, F. Giordano, I. Orabona and A. Vitagliano, Chem.-Eur. J., 2000, 6, 1127. 